\title{
Chapter 23 \\ Beyond the Traditional: Academic \\ Integrity in Canadian Librarianship
}

\author{
Leeanne Morrow (D)
}

\begin{abstract}
Academic integrity and information literacy concepts are interwoven throughout academic processes. In Canada these are reflected in both secondary and postsecondary assessment environments. Academic librarians are well positioned within and beyond the academy to promote a culture of academic integrity to postsecondary and high school students. In 2008 authors Drinan and Bertram Gallant addressed the opportunity for librarians to take an active role in building a culture of integrity stating "The issue of plagiarism is one that cries out for the active participation of librarians not only in the academic integrity systems on their respective campuses, but also in the national and international academic integrity movement" (p. 137). The question is where are librarians in this movement in Canada? Beyond plagiarism, how far have librarians come in their involvement in academic integrity culture both on and off Canadian campuses? This chapter will look beyond the librarian's role in teaching information literacy and its principles in the classroom to further examine the inroads being made as an active partner with campus services and students in our communities. Connections between ACRL's six information literacy frames and academic integrity with a specific focus on "Scholarship as Conversation" and the role students' play in this process will be highlighted. Librarians have a pivotal role to play in moving the academic integrity conversation forward. Through their understanding of critical and ethical use of information they can be at the forefront of advocating for integrity in academic work and assisting in the success of students on and off campus.
\end{abstract}

Keywords Academic integrity • Information literacy • Outreach • Librarianship • Plagiarism $\cdot$ Citation $\cdot$ Canada

\footnotetext{
L. Morrow ( $\varangle)$

University of Calgary, Calgary, Canada

e-mail: leeanne.morrow@ucalgary.ca
}

S. E. Eaton and J. Christensen Hughes (eds.), Academic Integrity in Canada, 
The professional work librarians do can often be a mystery to the campus community. The traditional perception of the library on campus is still often centered on its role as a research collection. Librarians have long been a profession that is well positioned to support the institutional goals of the university including supporting learners and researchers in navigating the vast information landscape of academic research. Combatting plagiarism and promoting proper attribution of sources is the one component of academic integrity that can be vital to both the research and teaching mission in post-secondary environments (Drinan \& Bertram Gallant, 2008). This can easily be addressed by librarians through their information literacy instruction both inside the classroom and online. How do librarians in Canada support academic integrity in the academy? Are they adequately supporting the institutions priorities in this area? Are there any developments beyond librarians working solely in the area of teaching students about plagiarism and citation? This chapter will examine these question in addition to looking at opportunities for further development by research and learning library professionals across Canada.

\section{Academic Integrity and Information Literacy}

The International Centre for Academic Integrity has one of the most commonly accepted definition of academic integrity "as a commitment, even in the face of adversity, to six fundamental values: honesty, trust, fairness, respect, responsibility, and courage. From these values flow principles of behavior that enable academic communities to translate ideals to action." (International Centre for Academic Integrity, 2014).

The Association of College and Research Libraries (ACRL) has the most accepted and embraced definition for information literacy in North America:

Information literacy is the set of integrated abilities encompassing the reflective discovery of information, the understanding of how information is produced and valued, and the use of information in creating new knowledge and participating ethically in communities of learning. (American Library Association, 2015)

The foundational framework built around this definition to guide when teaching learners has six frames. These frames include:

1. Authority Is Constructed and Contextual

2. Information Creation as a Process

3. Information Has Value

4. Research as Inquiry

5. Scholarship as Conversation

6. Searching as Strategic Exploration

Within this identified framework learning and modelling information literacy behaviours are further broken down to knowledge practices and dispositions. The core principles around academic integrity show up throughout these frames (American 
Library Association, 2015). It is evident that these two definitions are connected and play an important role in the life of learners on campuses around the world. Academic integrity is most clearly embedded into the frame "Information Has Value". This frame and its dispositions indicate that learners will understand their role as "creators and users" of information particularly in a scholarly conversation (ACRL). The learner in this frame acknowledges the importance placed on citation and their responsibilities in respecting the ideas of others (ACRL). Frame number 5 centering on "Scholarship as Conversation" is another connection point where academic integrity values and practices appear in the information literacy framework. Here librarians can teach learners how to see themselves as active contributors to scholarly conversations through their work as researchers and writers. This is where researchers and writers will produce works that appropriately give credit to others in the field in which they are writing but also read in a discipline and identify works of knowledge that are authoritative and creditable in their field (American Library Association, 2015). The two definitions can exist nested together. It is important for learners and researchers to understand that you cannot consider a student population to be information literate unless they understand ethical knowledge creation. When our students of all ages can see they play a role in writing and citing in scholarly conversations where they contribute to knowledge creation, they can also see the importance placed on doing so with integrity.

As Lokse et al. (2017) share in their chapter on academic integrity in Teaching Information Literacy in Higher Education academic integrity not only helps to develop information literate students decision making skills it also helps ensure creditability in the future "production of new knowledge". Lokse et al. (2017) point out that helping students to understand they are not just empty vessels that are filled with new knowledge, but rather active participants in its production will further their motivation to comply with the "norms of academia" (p. 70). The authors build a strong connection between understanding academic integrity and its connections to research integrity.

"First, dealing with academic integrity is about the quality of student learning and formation. Second it is about the production of original, reliable and valid knowledge. The connection is that today's students are the future producers of new knowledge" (Lokse et al., 2017, p. 74). When librarians connect information literacy to academic integrity it strengthens students skill set. Thinking about the nesting of academic integrity within information literacy brings forth McCabe et al.'s (2012) notion of the "hidden curriculum". They address creating a "hidden curriculum" (p. 177) meaning offering student the opportunity to learn and practice academic integrity skills outside the classroom or outside obvious ethics courses. Often information literacy sessions offered by librarians give students the opportunity to discuss and explore issues related to whether a source is a "good" source, whether it's been created by an expert who can be trusted, or where and when we need to give credit to others in our research and writing. During these types of sessions students are developing their skills in a non-obvious, almost hidden way. 


\section{Plagiarism in the Canadian Context}

In 2003 Christensen Hughes and McCabe conducted a study looking at the academic integrity behaviours and choices amongst Canadian post-secondary students. Based on an original survey conducted by the Center for Academic Integrity data was collected from eleven higher education institutions in Canada. This study was interesting in that it asked students to reflect on their experience in high school in addition to their experiences as an undergraduate or graduate student. One important finding from this critical work was that $73 \%$ of the participants admitted to cheating on written work (Christensen Hughes \& McCabe, 2006, p. 8). Speaking to the role librarians can play around citing properly it should be noted that this study found that those students commonly reported improper citation or not citing at all while in high school. Christensen Hughes and McCabe (2006, p. 8) found similar results in the data from the undergraduate experience responses around citation but the number of students who admitted to this type of misconduct was much lower. The results from graduate students included the notable finding that $6 \%$ admitted to "fabrication or falsification of lab data" (p. 11). Librarians need to acknowledge that this happens in postsecondary environments to explain the implications on the breakdown of the scholarly conversation when data is manipulated as part of information literacy instruction.

\section{The Librarian's Role}

There is substantial literature centering on librarians' roles in advocating and educating around academic integrity, particularly coming from North American authors and researchers. In 1988 a foundational piece by Lorna Peterson (1988) examined traditional bibliographic instruction librarian's role in teaching about plagiarism. Lampert (2008) shares an overview of original research, including that of Peterson (1988), but with the addition of works by Auer and Krupar and Brandt that includes the early work around examining librarians, information literacy instruction and ethical use of information. Reviewing the developments over the last decade the major focus of the literature is on librarians work in preventing, detecting and educating around the topic of citation and plagiarism. Many authors have noted the critical (if often over looked) role a librarian can play in the integrity strategy of post-secondary institutions (Drinan \& Bertram Gallant, 2008; Germek, 2009; Lampert, 2008; Synder Gibson \& Chester-Fangman, 2011). As Synder Gibson and Chester-Fangman (2011) note librarians have been included in some of the broader literature around academic integrity but primarily the focus has been on plagiarism and the use of the librarians skills set in detecting possible plagiarized sources. Drinan and Bertram Gallant (2008) have a firm understanding of the role of librarians in helping students wade through the massive volume of information available to them in print and online. They point out the advantages the librarian has in being able to see and understand 
the skills it takes to navigate the twenty first century information landscape in a particular discipline (127). Germek (2009) suggests a laundry list of areas librarians should and could work in to improve the culture of integrity on campus. They specifically suggest that there should be a "comprehensive strategy" by the library to look at its role throughout the learning process around inhibiting plagiarism including using our online platforms like Libguides, our instruction sessions (moving beyond the one shot sessions), reference desk interactions addressing citations, and providing more workshops (p. 342).

\section{Information Literacy and Academic Integrity Moving Beyond the Classroom}

Synder Gibson and Chester-Fangman (2011) suggested that librarians partner with other units on campus to fully address academic integrity in the classroom and use these relationships to further their role at the institutional level. They suggest looking at building awareness of academic integrity policy on library websites and integrating into the information literacy instruction in the classroom. Both Germek (2009) and Greer et al. (2012) agreed that moving to an institutional approach to information literacy and academic integrity across all programs on campus, and extended information literacy sessions beyond the "one shot" that librarians normally offer should be a priority to help fix the problems of plagiarism. Germek (2009) claims ACRL's addressing of plagiarism is weak and could be improved. To test his theory that librarians are less likely to speak to students in their general instruction sessions about the importance of academic integrity and plagiarism he designed a survey for freshman composition teachers asking "is plagiarism commonly discussed by your librarian during instructional library sessions?". The results from this survey revealed that only $36.6 \%$ of librarians covered the topics of plagiarisms during class time. Germek (2009) found that often it was assumed that teaching about plagiarism was someone else's area of focus such as high school teachers or the instructors and not the librarians (Germek, 2009).

Synder Gibson and Chester-Fangman (2011) developed a survey sent to librarians and library staff in the United States asking them about their experience with plagiarism in the classroom. Three areas were of particular interest to the researchers:

1. Role that librarians are assuming in institution wide effort to combat plagiarism

2. Collaborations between librarians and instructors seeking to address this issue and

3. Approaches that librarians are using to teach students to avoid plagiarism. (p. 136)

610 librarians from across the United States completed the survey with participants primarily from post-secondary and a smaller percentage from school and public settings. The results were interesting in painting a clearer picture about libraries and their librarians' involvement with anti-plagiarism instruction in the US. Even a decade ago, when asked whether librarians should have a role in teaching about 
plagiarism, 530 respondents indicated that it was a part of a librarian's role. Roughly a third of all respondents to the survey indicated they participated in the development of their institutions approach to plagiarism through policy development. 50\% of those who responded said they had partnered with faculty or departments to address issues of plagiarism one to five times a year. And two thirds of the respondents indicated they had been asked to take part in an "investigation" around student plagiarism (Synder Gibson \& Chester-Fangman, 2011). This makes sense when considering the literature around the commonly held belief that librarians are often considered as experts when it comes to taking on a detective role in plagiarism cases.

Appearing around 2004-2006 the possibility of taking academic integrity instruction online begins to emerge in the library literature. As Jackson (2006) notes in one of the first published articles looking specifically at online plagiarism tools "Webbased information literacy tutorials allow students to learn important research skills at their own pace, outside traditional class time and classrooms" (p. 419). The article describes a project at San Jose State University looking at the possibilities of the library and partners developing more tools to support students in their learning around plagiarism. Outside of the traditional class based instruction much of the literature has focused on building and sharing library led online plagiarism tutorials. Based on his analysis of the results from his 2009 study Germek suggested using library technology to not only define academic integrity but to produce tools that can show students first hand examples. One prominent early example from 2012 was the tutorial developed at the Oakland University Library and Writing Centre (Greer et al., 2012). This successful 6 part tutorial was developed by a collaborative task force specifically looking at building learning outcomes based interactive tutorials for all students at the University. It was one of the first articles to suggest the benefits of embedding the tutorials into the learning management software of institutions (Greer et al., 2012). Since these early developments tutorials have grown in numbers and can be found on library websites across North America. Building on the advice and research shared by these authors and researchers since 2006 librarians have often partnered with Writing Centre or Student Service units on campus to create add on tutorials when requested by the institution or when the librarians felt the one hour instruction session was not enough time to cover the topics of plagiarism and citation (Greer et al., 2012; Diamond, 2019; Park et al., 2011; Evers Ard \& Ard, 2019; Creed-Dikeogu, 2018). Tutorial development seemed to be the next logical step in supporting students beyond the classroom.

\section{Environmental Scan-Canadian context}

Although there is not a great deal of literature around librarians' role in academic integrity systems in Canada, there are very good examples that highlight in roads and advancements that have been made by Canadian librarians in the last decade. Many institutions are working to enhance the student experience around academic integrity through the library. Liu and Pillon (2016) share their experience delivering 
in person workshops to international students at the University of Windsor and their move to building ACRL information literacy framework based online modules for further student learning around plagiarism. Sheridan College is a good example of an institution that has a strong in person and online support for academic integrity through their first-year librarian program (Goodfellow et al., 2018). Their partnership between the Library and Writing Centre allows for the integration of information literacy skills around plagiarism throughout their work with students. The University of Manitoba liaison librarians are working with students to provide postdiscipline education around citing, reference style and managing sources effectively (Albrecht et al., 2020). Expansion of their work with students will include building more supports around critical reading, understanding sources and sharing the value of working with librarians. The author's own institution provides opportunities for librarians to work with students who have academic misconduct violations. Four librarians partner with the Academic Integrity Coordinator and the Student Success Centre to develop and teach sessions addressing plagiarism and how to avoid it as well as inappropriate collaboration. Additionally their work promoting an understanding of contract cheating around the International Day of Contract Cheating is a valuable contribution to campus discussions. This important day every October has become a regular occurrence on many campuses throughout Canada and around the world. A scan of Twitter and the hashtag \#defeatthecheat shows libraries and their staff from across Canada taking an active role in this important academic integrity initiatives. Ideas range from workshops to interactive, learning displays to contests. Libraries often encourage their student peer volunteers to be involved in this day and have them engage one-to-one with students in the library around academic integrity.

Reviewing the websites of many Canadian post-secondary libraries and particularly the library websites of Canada's U15 can provide some context around the depth of support for academic integrity offered through the libraries. The U15 universities are a group of research intensive postsecondary institutions in Canada. The library websites of thirteen institutions of the U15 had strong content promoting academic integrity and as one might guess the focus was on citation and plagiarism. Almost every U15 library site displayed some formal connection to the University's academic integrity office, handbook or institutional definition through links from research support tools such as Libguides. Some libraries showed evidence of an expanded role around academic integrity such as UBC's Chapman Learning Commons. This unit within UBC's library system is taking the library lead on academic integrity and has developed extensive resources around various aspects of academic integrity including general citation, citing data and respecting copyright. Their role has developed over a long period of time as their work was noted in Drinan and Bertram Gallant in 2008.

It is evident when reviewing the U15 library sites that many librarians and library staff have contributed to the development of online academic integrity tutorials or videos. Most tutorials or videos explicitly highlight the library's contribution but are built in partnership with campus writing support services units. The Foundational Research Tutorials developed by the University of Alberta Libraries showcase a great example of the libraries contribution these types of learning tools. They scatter topics 
related to academic integrity throughout their series and finish with a plagiarism module. Beyond the U15 websites a simple Google search of "academic integrity and tutorials and library and Canada" will bring forth outstanding academic integrity contributions from libraries across the country. An example of cross unit collaboration based in a Learning Commons is York University's SPARK (Student Papers and Academic Research Kit) an e-learning tool which features material developed by the Learning Skills Centre, the Learning Commons and the Writing Department. University of Waterloo Library's "Academic integrity tutorial" features definitions and scenarios for students to work through around academic integrity. They feature the option to "chat" with the library on the tutorial page which is a great example of connecting services to modules for further learning. These are just a few examples of the work that libraries are taking part in on campuses throughout Canada.

Many Canadian librarians have begun to take part in the publishing stream around academic integrity. Of particular note is the 2020 Kwantlen Polytechnic University Pressbook "Academic Integrity" created by librarian Ulrike Kestler (see Kestler, 2020). This open access book covers topics like understanding academic integrity, understanding plagiarism, how to avoid plagiarism through both proper referencing and practicing proper writing skills. Within this interactive book you will find short readings, quizzes and other activities students can do to engage in these topics. This type of new resource can be shared and used by other institutions is an outstanding example of ways Canadian librarians can and should be contributing to the academic integrity conversation nationally. Another in-press title coming soon is Academic Plagiarism: Librarians' Solo and Collaborative Efforts to Curb Plagiarism. This title edited by Rysavy and Michalak will include multiple chapters from Canadian librarians working at institutions across the country.

\section{Observations and Opportunities}

\section{Academic Librarians and High Schools}

As many librarians and faculty members know writing and research can be a challenge for first year students entering post-secondary right out of high school. Many students come to university without having had experience in citing and writing. Many enter without highly developed information literacy skills. Rather than trying to place blame anywhere there is an opportunity for librarians to play a role in reaching out to local high schools. Highlights from McCabe's initial research in 1999 with junior high school students found that there were lessons to be learned from the self-reported academic integrity experiences. He found evidence to support the belief that cheating habits developed early. Initial results from the surveys included that $74 \%$ of junior high students admitted to cheating on a test. Initiating a second, larger survey in 2000 McCabe et al. (2012) found $81 \%$ of junior high students reported some form of test cheating or one or more instances of plagiarism. 
With the knowledge that there are academic integrity challenges early in a student's life what role can libraries play in mitigating this? A recent article from Pennsylvania Libraries: Research and Practice reports on the decline of librarians in public schools in the United States and demonstrates how this loss of library expertise can negatively impact those entering their first year at a university or college (Lysiak, 2020). Various innovative projects are highlighted in this article to meet the needs of transitioning first year students including building modules around citing and writing and developing embedded mandatory modules across the curriculum. Seeing similar challenges at their institution in Louisana, Magale Library at Centenary College in 2012 began offering three different outreach opportunities to local high schools and their school librarians to help increase students comfort and familiarity with academic integrity and information literacy skills (Wrenn \& Kohl, 2012). These community outreach programs included building professional development opportunities for local school and public librarians around academic integrity and offering supplemental instruction to student transitioning from high school to university. In reviewing Canadian academic library websites, it is evident that many post-secondary libraries offer spaces and collection access to high school students in Canada. There are institutions such as York University, University of Toronto, University of Victoria and University of Calgary which go a step further to offer on-campus information literacy instruction to their local high school student population. This extra preparation gives prospective students not only an introduction to campuses and spaces but also to introductory research experiences. Having some familiarity with information literacy and academic integrity before entering first year can definitely benefit students. Many universities and colleges in Canada include institutional goals of reaching out to the community. Many of their libraries have outreach librarians whose work it is to fulfill the library side of this community engagement. Providing opportunities for local high school students to experience researching, writing and citing through working with librarians on campuses is a great way to prepare student early for their post-secondary life. Christensen Hughes and McCabe (2006) suggested "Perhaps greater collaboration is needed between high schools and universities..." (p. 16). Time spent reaching out to high schools can lead to better academic integrity outcomes.

There is very little North American literature on post-secondary outreach programs to high schools on academic integrity. Wagg and McKinney (2020) researchers in the UK, investigated the value of outreach programs between higher education institutions and high schools specifically looking at aspects of information literacy programming. Their findings indicate that this kind of program "is an effective mechanism for bridging the social worlds of schools and higher education; for creating partnerships and knowledge sharing between institutions; for breaking down social barriers and inequalities; and for developing critically aware, independent learners" (p. 63). 


\section{Establishing an Effective Outreach Program}

Often higher education institutions in Canada have strategic goals that focus on connections with surrounding communities. These goals are often met through strategic research partnerships. At the University of Calgary the Libraries and Cultural Resources unit implements community engagement strategic goal by supporting students and teachers in the K-12 environment through the delivery of a well-established outreach program. Students from eight high schools throughout the city of Calgary visit the Library at the University of Calgary at least twice a year, sometimes up to four times a year, to learn about and build hands-on skills in all aspects of information literacy. All classes are taught by librarians and staff who work with the students through the research process from finding a question, through looking for background information, to citation. Over the years of teaching in this outreach program visiting teachers and their school administration expressed a keen interest in having the librarians extend the information literacy focus to cover the interrelated topic of academic integrity. This opening allowed for the development of a more complete program around academic integrity for interested high schools, their students and their teachers. Schools now have the option to attend both the information literacy component of the program and the academic integrity piece. Some schools have requested the academic integrity piece be offered as a separate class which the librarians are able to deliver online.

What makes this an effective, accessible program at the University of Calgary? Part of the effectiveness is related to what Wagg and McKinney (2020) identify as barriers. In their research schools identified "taking time out of the curriculum, staffing and resources and cost of travel" as reasons for not taking part in outreach opportunities for their students in regard to building information literacy skills (61). The high school information literacy and academic integrity program at the University of Calgary works to eliminate as many of the barriers as possible. It has shifted entirely online during the COVID-19 pandemic and will remain as an online option for schools who may not be able to visit the campus due to transportation costs and logistics. Additionally the resources and staffing for this outreach program are entirely provided by the librarians and staff at the University. The librarians and staff work with the teachers to plan how the classes will relate to the curriculum. Addressing these barriers helps to ease the access to effective learning for students in both the information literacy arena as well as academic integrity.

To establish a program like this there are some key factors that will make success more likely. First, the initiative should support institutional goals such as engaging with the community and recruitment. Second library administration working with interested librarians should identify how the program can address those goals and their own priorities. A priority for the University of Calgary library is to give incoming students an advantage in understanding more about academic integrity and information literacy before entering first year. The goal at the University of Calgary is not only to build skill sets around research, critical thinking and integrity awareness but to showcase the University to the students and give them some idea of 
what the expectations will be for future work in a post-secondary environment. This can speak to the University's focus on recruitment. McCabe et al. (2012) suggest creating marketing material that can be used when promoting your institution during recruitment activities to high schools and highlighting the culture of integrity that is in place and the expectations required in your educational institution. Applying this lens to the creation of an academic integrity outreach program one might think of the instruction delivered by librarians to high school students as the marketing material and the opportunity to showcase the culture at your institution. Third, the initiative needs to address real needs in the community. In Calgary, there are very few professional librarians working in the school system, and therefore little formal information literacy instruction. Some schools have seen the program as a way to fill this gap in their students' education and give them advantages as graduates. Fourth, operationally it is helpful to identify both librarians and library staff interested in assisting with the program. Having more than one librarian able to teach academic integrity content allows for flexibility in program hours and offerings. Developing fluency in all aspects of academic integrity, beyond citation and plagiarisms is also crucial. Building from general cheating and plagiarism questions students will ask everything from "what happens if I have a violation"to very specific "how I can paraphrase better so I don't plagiarize". Having staff and librarians who can answer these questions is important. Having other administrative supports such as an online intake form is useful. This allows schools to share information in advance and works for the planning process. Building on what is offered for students, there is the potential to offer professional development opportunities for teachers in K-12 around academic integrity. This can be done by reaching out to the schools and school board administration to offer opportunities both in person and online to develop better awareness of academic integrity challenges. The University of Calgary has recently expanded its professional development offerings to include a full day workshop on academic integrity awareness in K-12 offered through a partnership between a librarian and faculty member in the school of education.

Considering the overall goals for your institution, staffing, community needs and what you need operationally is important to establishing a successful academic integrity outreach program. By doing this pre-first year preparation your library and librarians are contributing to recruitment and retention of students in first year.

\section{Moving Beyond Plagiarism}

The literature indicates librarians in Canada and North American are actively contributing to the areas of education around traditional definitions of plagiarism and citation on their campuses. But what about other aspects of academic integrity? There seems to be little evidence of librarians working with students to understand their role in academic misconduct like falsification or fabrication of data or collusion. As Drinan and Bertram Gallant (2008) suggest, because librarians critically evaluate, 
accumulate, store and share information and intellectual property they are well positioned to act as "key agents of coherence in the rapid flows of intellectual experience" (p. 127). This role beyond plagiarism and citation can be expanded to include more support for the foundational understanding of knowledge creation. In turn this can lead to embracing both academic integrity and information literacy. When working with students to help them understand the importance placed on producing data that is trust worthy and accurate, librarians can share their vast knowledge of the current and past "misinformation" or "fake news" world. When students can relate and see the impact misinformation has had on their own lives and how data that has been falsified can impact the planet, they seem to be able to value academic integrity more highly in their work. Both University of Calgary and University of Manitoba have librarians working with students who have been disciplined for academic misconduct. The University of Calgary librarians deliver the mandatory courses that are required to be completed after a violation occurs. These courses explore the student's role in creating knowledge and actively contributing to the truthful scholarly conversations in their field. The University of Manitoba librarians meet one-to-one with students who have been disciplined for academic misconduct to build their citation and research skills (L. Gervais, personal communication, December 14, 2020). Many librarians across the country are untapped resources when it comes to working with students as part of academic misconduct consequences. Their expertise in information literacy and citation band their understanding of knowledge creation itself to the role of educating those students who have encountered challenges.

\section{Additional Programming}

Libraries are intended to be a space for dialogue and engagement. There are opportunities to use library spaces as venues for more dialogue around academic integrity and as aspects related to this topic. The topic of building students' identity as authors is a crucial area more libraries could play a role in. "authorial identity" is defined by Elander et al. (2010) as "the sense a writer has of themselves as author and the textual identity they construct in their writing" (p. 159). According to Elander et al. there is evidence in the literature looking at the connection between accidental or unintentional plagiarism and lack of strong authorial identity. In their research, these scholars looked at implementing an intervention that explored building the confidence and identity of students as authors as well as providing instruction in some of the mechanics of avoiding plagiarism including proper paraphrasing. They measured using 6 different scales including: confidence in writing, understanding authorship and knowledge to avoid plagiarism. The results from this study indicated that educating students early in their learning journey around the topic of authorial identity and their specific role in writing as well as giving them some understanding of plagiarism had a positive impact in reducing unintentional plagiarism. From this research $66 \%$ of students reported they wrote better assignments and $86 \%$ of students 
reported they believed the interventions helped them avoid plagiarism (Elander et al., 2010).

So how would libraries contribute to building authorial identity? Cheung et al. (2018) explored this same topic but focused on the experiences and beliefs held around authorial identity by academics. Results from their qualitative exploration included a discussion of "authorial goals" or goals set out by the writer that focus on intention and communication rather than on writing for a grade. Results from this study suggested if students were able to understand writing as contributing to the construction of new knowledge rather than solely as mimicking models of academic writing in their discipline, then a more authentic, intentional voice would emerge. As one participant claimed "There's a huge difference between having writing skills and actually being a writer" (p. 1476). The finding also indicated that a possible way to indirectly support students' academic integrity goals of avoiding plagiarizing would be to emphasize respecting the community they are writing in. This could be done through embedding students in activities where they see themselves as active authors in their discipline community (Cheung et al., 2018). Librarians can explore options of more programming around providing opportunities for students to hear directly from academic writers about their experiences. The library could host events where students, both undergraduate and graduate, are offered the opportunity to present their writing and their research to others on campus. As Cheung et al. (2018) suggest this gives them the opportunity to perceive "oneself as part of the academic community" (p. 1480). Librarians can encourage this type of confidence building by working with discipline based classes to explore the non-academic literature in a subject. This could involve students reading and discussing not only the validity and truthfulness in say, a blog post, but also the writing style of the author (Cheung et al., 2018). Putting a focus on the priority of respecting themselves as authors, understanding the community in which they are writing both speaks to the ACRL frame of "Scholarship as a Conversation" and the disposition that students see themselves in as builders of new knowledge with a responsibility to enter into the conversation by respecting and valuing the contribution of others. (American Library Association, 2015). Librarians can build the skill sets of students as authors and in turn contribute to students writing better, more truthful assignments by seeing the connections and the opportunities they have in their role as educator both inside and outside the classroom.

\section{Conclusion}

Librarians understanding of the research process and how knowledge is created and shared give them the perfect perspective to take a leading role in the development of academic integrity in schools and on campuses everywhere. When offered a seat at the table both at the curriculum development level and the policy development level a librarian can contribute their unique perspective of helping dig into the value base around research and academic integrity (Lokse et al., 2017). Librarians can expand their role and share their expertise in understanding academic integrity at a 
broader institution-wide level as Drinan and Bertram Gallant state "librarians should see themselves as active, indeed proactive, participants in the design and operation of academic integrity systems" (2009). How can librarians become more involved in academic integrity? Reach out to the campus units involved in this area such as writing support services, teaching and learning centres or student services. Ask them to partner with the library on developing more in person and online supports. Make a connection with the units that do recruitment on campus to share information around classes that the library can offer to high schools to promote recruitment. Ensure the library's online guides and website always point to the institution's policies on academic integrity. Finally make sure the discipline-based instruction offered by liaison librarians embeds some elements of academic integrity into the curriculum and highlight this to faculty.

Academic librarians in Canada are taking a more proactive role both online and in person in contributing to the supports offered on campuses to students around academic integrity. They are offering workshops, building tutorials and becoming a central source of support and expertise for students and faculty. While their experience may lie in a more traditional role as educator around citation and information literacy, this can be expanded into assistance around other integrity topics like inappropriate collaboration or falsification and fabrication. There are untapped opportunities for Canadian librarians and libraries to contribute to the more holistic experience of academic integrity including offering outreach to the greater community to better prepare students for a post-secondary learning experience as well as expanding programming in libraries to cover broader skill development around research and writing. It is encouraging to see the expanding role librarians are taking in Canada and around the world in academic integrity. They bring a unique perspective to the academic integrity systems in post-secondary environments everywhere.

\section{References}

Albrecht, V., Clark, S., \& Winkler, J. (2020). Sweet dreams? Librarians' roles in academic integrity. OLA superconference. http://accessola2.com/superconference2020/Sessions/2Thurs Jan30/OLASC_Sweet\%20Dreams.pdf

American Library Association. (2015). Framework for information literacy for higher education. http://www.ala.org/acrl/standards/ilframework

Cheung, K. Y. F., Elander, J., Stupple, E. J. N., \& Flay, M. (2018). Academics' understandings of the authorial academic writer: A qualitative analysis of authorial identity. Studies in Higher Education, 43(8), 1468-1483. https://doi.org/10.1080/03075079.2016.1264382

Christensen Hughes, J. M., \& McCabe, D. L. (2006). Academic misconduct within higher education in Canada. Canadian Journal of Higher Education, 36(2), 1-21.

Creed-Dikeogu, G. F. (2018). The politics behind the library plagiarism tutorial: A case study. Kansas Library Association College and University Libraries Section Proceedings, 8(1), 1. https:// doi.org/10.4148/2160-942X.1071

Diamond, K. (2019). Rejecting the criminal narrative: Designing a plagiarism avoidance tutorial. Journal of Electronic Resources Librarianship, 31(4), 232-240. https://doi.org/10.1080/194 1126X.2019.1669962 
Drinan, P. M., \& Bertram Gallant, T. (2008). Plagiarism and academic integrity systems. Journal of Library Administration, 47(3-4), 125-140. https://doi.org/10.1080/01930820802186472

Elander, J., Pittam, G., Lusher, J., Fox, P., \& Payne, N. (2010). Evaluation of an intervention to help students avoid unintentional plagiarism by improving their authorial identity. Assessment and Evaluation in Higher Education, 35(2), 157-171. https://doi.org/10.1080/02602930802687745

Evers Ard, S., \& Ard, F. (2019). The library and the writing centre build a workshop: Exploring the impact of an asynchronous online academic integrity course. New Review of Academic Librarianship, 25(2-4), 218-243. https://doi.org/10.1080/13614533.2019.1644356

Germek, G. P. (2009). Imagine no possessions: Librarians, the net-generation student, and the imminent victory of plagiarism. College \& Undergraduate Libraries, 16(4), 338-357. https:// doi.org/10.1080/10691310903356000

Goodfellow, J., Traynor, M., Palombi, D., \& Clark, A. (2018). Promoting and Supporting Academic Integrity at Sheridan College. Publications and Scholarship. 7. https://source.sheridancollege.ca/ 1ls_publ/7

Greer, K., Swanberg, S., Hristova, M., \& Switzer, A. T. (2012). Beyond the web tutorial: Development and implementation of an online, self-directed academic integrity course at Oakland University. The Journal of Academic Librarianship, 38(5), 251-258. https://doi.org/10.1016/j. acalib.2012.06.010

International Centre for Academic Integrity. (2014). Fundamental Values. https://www.academici ntegrity.org/fundamental-values/

Jackson, P. A. (2006). Plagiarism instruction online: Assessing undergraduate students' ability to avoid plagiarism. College \& Research Libraries, 67(5), 418-428. https://crl.acrl.org/index.php/ $\mathrm{crl} /$ article/view/15820

Kestler, U. (2020). Academic integrity. Kwantlen Polytechnic University. https://kpu.pressbooks. pub/academicintegrity/

Lampert, L. D. (2008). Student academic integrity. In C. Cox \& E. Blakesley Lindsay (Eds.), Information literacy instruction handbook (pp. 149-163). American Library Association.

Liu, G., \& Pillon, K. (2016). Enhancing international students' library and academic skills at the University of Windsor, Canada. International Leads, 30(3), 7-8.

Lokse, M., Lag, T., Solberg, M., Andreassen, H. N., \& Stenersen, M. (2017). Teaching information literacy in higher education: Effective teaching and active learning. Chandos Publishing.

Lysiak, L. (2020). Academic integrity: Developing an approach students can own! Pennsylvania Libraries: Research \& Practice, 8(1), 58-63. https://www.palrap.org/ojs/index.php/palrap/art icle/viewFile/217/785

McCabe, D. L., Butterfield, K. D., \& Trevino, L. K. (2012). Cheating in college: Why students do it and what educators can do about it. John Hopkins University Press.

Park, S., Mardis, L. A., \& Ury, C. J. (2011). I've lost my identity-oh, there it is... in a style manual: Teaching citation styles and academic honesty. Reference Services Review, 39(1), 42-57. https:// doi.org/10.1108/00907321111108105

Peterson, L. (1988). Teaching academic integrity: Opportunities in bibliographic instruction. Research Strategies, 6(4), 168-176.

Synder Gibson, N., \& Chester-Fangman, C. (2011). The librarian's role in combating plagiarism. Reference Services Review, 39(1), 132-150. https://doi.org/10.1108/00907321111108169

University of Alberta (n.d.). Foundational Research Tutorial. https://www.library.ualberta.ca/tutori als/foundational

University of Waterloo (n.d.). Academic Integrity Tutorial. https://uwaterloo.ca/library/researchsupports/academic-integrity/academic-integrity-tutorial

Wagg, S., \& McKinney, P. (2020). Information literacy outreach between universities and schools: A case study. Journal of Information Literacy, 14(2). https://doi.org/10.11645/14.2.2692 
Wrenn, C., \& Kohl, K. (2012). Ensuring academic integrity through community and campus outreach. Codex: The Journal of the Louisiana Chapter of the ACRL, 2(1), 58-70. http://jou rnal.acrlla.org/index.php/codex/article/view/64

York University (n.d.). Student papers and academic research kit. https://spark.library.yorku.ca/aca demic-integrity-using-and-citing-sources/

Leeanne Morrow is the Associate University Librarian, Student Learning and Engagement at the University of Calgary. She holds a Master's degree in Library and Information Studies from the University of Alberta and a Bachelor of Arts in Art History from the University of Calgary.

Open Access This chapter is licensed under the terms of the Creative Commons Attribution 4.0 International License (http://creativecommons.org/licenses/by/4.0/), which permits use, sharing, adaptation, distribution and reproduction in any medium or format, as long as you give appropriate credit to the original author(s) and the source, provide a link to the Creative Commons license and indicate if changes were made.

The images or other third party material in this chapter are included in the chapter's Creative Commons license, unless indicated otherwise in a credit line to the material. If material is not included in the chapter's Creative Commons license and your intended use is not permitted by statutory regulation or exceeds the permitted use, you will need to obtain permission directly from the copyright holder.

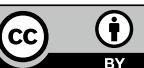

